\title{
O MAPA DE HAMY: CARTA DO Dr. ALBERTO KRAFT.
}

Recebemos e estampamos, como nos foi solicitado, a seguinte carta do Dr. Alberto Kraft, da "Guillermo Kraft Ltda. Soc. Anón. de Impresiones Generales", de Buenos Aires:

Buenos Aires, 14 de mayo de 1958.

\author{
Señor Director de la \\ "Revista de História" \\ doctor E. Simões de Paula \\ Rua Maria Antônia, 294 \\ San Pablo, Brasil.
}

Muy señor mío:

Le en el N..$^{\circ} 32$ de la Revista de História a su digno cargo, el artículo del Sr. Giuseppe Caraci, en el que alude a la Casa Kraft, respecto de un mapa incluído en "América la Bien Llamada" del Sr. Roberto Levillier, editada por nosotros. Expresa dudas acerca de nuestra parte en la aclaración de latitudes del mapa y juzga el hecho en forma tan punzante como inadecuada. Por esa razón solicito de la amabilidad de usted la inserción de estas líneas.

Lo que explicó el Sr. Levillier en algunos renglones de su artículo sobre el mapa de Maiollo, pubicado por esa Revista era exacto y me limito ahora a ampliar los detalles. Los dibujos y las fotografías del libro, pasaban de doscientos y los examinamos uno por uno como es costumbre de la casa para juzgar de su claridad. Por el escrúpulo del Sr. Levillier, de inscribir en los mapas líneas divisorias de jurisdicciones, o pegar escudos, nombres ade lugares $y$ cifras, el Jefe de taller fotográfico del departamento offset, indicaba los originales que no rendirian, a fin de que fuesen reforzados por el dibujante del Sr. Levillier. A fines de 1947, estaba en prensa el primer tomo y comenzábamos el segundo, cuando recibí del taller un lote de fotografias entre las cuales se hallaba el original del mapa de Hamy, impreso con autotipia y sacado de un libro, cuyo autor habł́ utilizado la obra de geógrafo francẹes. La mayoria 
de las latitudes eran ilegibles. El Sr. Levillier estaba en Europa, como lo recuerda en las páginas en que describe el viaje de Vespucio, (tomo II, págs. 325-330) y las fotografias le fueron enviadas a Londres, de donde las devolvió indicando que se reforzasen las cifras de latitud del lado izquierdo. Pesando, como ahora me entero, sobre dichas cifras, una circunstancia que era preciso conocer, es de lamentar que no nos dijese cómo había de cumplirse su indicación. El dibujante que las anotó, sólo tenia para guiarse, las del lado derecho, e intercaló iguales en el lado izquierdo. Ocurre ahora que era un error hacer eso que parecia tan justo, porque el autor del mapa habia marcado las cifras de latitudes de la izquierda, diferentes de las de la derecha. Las nuevas se dibujaron grandes, mejor dicho se escribieron con cifras gruesas y distintas de las otras, como se ven en las reproducciones de la Revista (N.*32). No es posible prestarles la intención de hacer creer que fuesen originales. La Casa Kraft, efectivamente, se interesa porque bajo su signo aparezcan las obras editadas con la máxima claridad, y recomendó aclarar, precisamente, para que en los dos tomos de la obra no hubiese un lunar. Esa fué la finalïdad perseguida. Esa es la verdad, y las quince páginas de deducciones del crítico anotadas con extraño ensañamiento caracen de consistencia, y por lo tanto, no merecen fe.

Al agradecer al señor Director la atención de la presente nota, lo mismo que de su disposición de publicarla en la Revista a su cargo, hago propicia la oportunidad para saludarle con mi mayor consideración. 